\title{
Prognostic significance of lymphatic invasion in lymph node-positive breast carcinoma: findings from a large case series with long-term follow-up using immunohistochemical endothelial marker
}

\author{
Rabab AA Mohammed ${ }^{1}$, Sindhu Menon ${ }^{2}$, Stewart G Martin ${ }^{3}$, Andrew R Green ${ }^{4}$, \\ Emma C Paish ${ }^{4}$ and Ian O Ellis ${ }^{4}$ \\ ${ }^{1}$ Department of Pathology, Faculty of Medicine, Assiut University, Assiut, Egypt; ${ }^{2}$ Department of \\ Histopathology, Royal Derby Hospital, Derby, UK; ${ }^{3}$ Department of Clinical Oncology, University of \\ Nottingham, University Hospitals, Nottingham, UK and ${ }^{4}$ Department of Histopathology, University of \\ Nottingham, University Hospitals, Nottingham, UK
}

\begin{abstract}
The poor prognostic significance of lymphatic invasion (LI) in breast carcinoma (BC) as a whole and in lymph node (LN)-negative patients in particular has been recognized in several studies; however, its prognostic role in LN-positive patients is still questionable. Aim of the current study was to assess prognostic role of $\mathrm{LI}$ in LN-positive BC specimens. Sections from non-selected 557 LN-positive BC specimens were stained with antibody to podoplanin/D2-40. LI was identified and correlated with clinicopathological features and patients' outcome. Twenty-year overall survival (OS), disease-free interval (DFI), and development of distant metastasis (DM) or recurrence were known for all patients. LI was detected in $262 / 557(47 \%)$ of specimens ranging from 1 to 350 lesion per tumor section. Its presence was associated with higher grade tumors $(P<0.0001)$, negative hormonal receptors $(P<0.0001)$, high HER-2 expression $(P=0.006)$, and with increased number of positive LNs $(P=0.019)$. In the whole $\mathrm{LN}$-positive $\mathrm{BC}$, presence of $\mathrm{LI}$ was a poor prognostic factor for OS, DFI, and development of DM both in univariate and in multivariate analysis. In further stratification of patients, LI was associated with poorer prognosis in patients with single positive $L N$ and not in patients with $>1$ positive $L N$. In T1N1 stage, LI was highly associated with poor OS $(P=0.002)$, DFI $(P<0.0001)$, and DM $(P<0.0001)$. In T2N1 patients, LI was associated only with poorer DFI $(P=0.037)$ but not with death or DM. In the two former patient groups, LI lost significance in multivariate analysis. In conclusion, $\mathrm{LI}$ is a poor prognostic factor in LN-positive BC particularly for patients having single positive $L N$. LI therefore would add further prognostic significance when considered in treatment in those patients. We recommend incorporation of $\mathrm{LI}$ in breast carcinoma staging and in prognostic indices.

Modern Pathology (2014) 27, 1568-1577; doi:10.1038/modpathol.2014.60; published online 25 April 2014
\end{abstract}

Keywords: lymph node-positive breast cancer; lymphatic invasion; lymphovascular invasion; podoplanin; prognosis

Accurate assessment of prognosis in patients with breast cancer is essential for proper selection of the best therapeutic options. Substantial research effort is being focussed on improving personalization of care in breast cancer with the aim of tailoring

Correspondence: Dr RAA Mohammed, PhD, MD, Department of Pathology, Faculty of Medicine, Assiut University, Assiut 7111, Egypt. E-mail: rabab_aamh@yahoo.com

Received 30 September 2013; accepted 12 March 2014; published online 25 April 2014 therapy for each patient. Although there has been considerable improvement in assessment of prognosis of breast cancer, there is still need to find and to optimize accurate prognostic and predictive factor(s) assessable in the primary tumor. Lymphovascular invasion is an important prognostic factor assessed in primary breast carcinoma (BC). Presence of lymphovascular invasion in a primary tumor has been used as an indication for the ability of this tumor to metastasis outside the breast. ${ }^{1}$ Such tumors therefore receive more intense therapy than 
tumors with no lymphovascular invasion in the same disease stage. ${ }^{2-4}$ The term 'lymphovascular invasion' refers to invasion of either blood vessels or lymph vessels. Invasion of any of these vessels by tumor cells is simply known as lymphovascular invasion. ${ }^{2}$ The current study used lymph vesselspecific marker (anti-podoplanin) for assessment of invasion of lymph vessels only and will be referred to as 'lymphatic invasion' (LI).

Evaluation of vascular invasion and its significant role in prognostication of breast cancer patients has received increasing interest in breast cancer research over the last years. ${ }^{1-7}$ In previous reports, LI was found to be independent poor prognostic factor in lymph node (LN)-negative breast cancer patients and has been recommended to be added to clinical management tools such as the 'Nottingham Prognostic Index (NPI)'.8 However, there still remains controversy in the literature regarding the relevance of assessment of vascular invasion in LN-positive BC. ${ }^{9-11}$ Although recent studies have found a significant prognostic impact for vascular invasion in LN-positive disease, ${ }^{12,13}$ methods for routine assessment of vascular invasion and standardization of its use in management are still in need for further assessment.

Aims of the following study were (a) to characterize LI in LN-positive breast cancers in terms of its frequency and distribution using immunohistochemical methods and (b) to assess in detail the prognostic role of LI in LN-positive breast cancer in a well-characterized large cohort of patients with long-term follow-up.

\section{Materials and methods}

\section{Specimens}

Five hundred and fifty-seven non-selected consecutive LN-positive primary BCs were identified from the Nottingham Tenovus Breast Cancer Series of women who presented with primary operable invasive BCs between 1990 and 1999. LN-positive in this study means positive axillary LNs regardless the status of other LNs. LN status was assessed by axillary clearance in 247 patients and by sampling in 210 patients. Specimens and clinical data were collected from the archive of the Department of Histopathology, City Hospital, Nottingham University Hospitals. The median age of patients at time of diagnosis was 52 years (range, 18-72 years). Patient's clinical history and tumor characteristics were retrieved from the database. This is a wellcharacterized series of patients treated uniformly in a single institution. Adjuvant systemic therapies were determined according to the NPI group. ${ }^{14}$ Survival data including survival time, disease-free interval (DFI), and development of distant metastasis (DM), local recurrence (LR) and regional recurrence (RR) was maintained on a prospective basis. Complete clinical follow-up information was available for all patients with ethical approval obtained for analysis from Nottingham Local Research Ethics Committee (REC C2020313). Patients were followed up at 3-month intervals initially, then at 6-month intervals. The maximum follow-up period was 246 months (range 4-246 months and mean 117). DFI was defined as the period from the end of primary treatment until the occurrence of any recurrence; local (defined as tumor arising in the treated breast or chest wall), regional (defined as tumor arising in the axillary or internal mammary LNs), or distant (any remote site other than local and regional). Any of these recurrences was scored as an event with censoring of other patients at the time of last follow-up or death. Overall survival (OS) was defined as the period from primary surgery until death of the patient.

\section{Immunohistochemical Staining and Assessment of LI}

For each specimen, all H\&E-stained sections were examined microscopically for selection of one representative section. Then the matching paraffinembedded block of the specimen was identified and collected. One section was cut from each of the representative blocks for the 557 specimens and stained with antibody to podoplanin/D240 (polyclonal, 11-003, AngioBio, CA, USA, 1:100 dilution). Detailed staining technique was described previously. ${ }^{15}$

LI was discerned by the presence of tumor cells within podoplanin-positive vessels. Number of LIs per section was identified and was referred to as 'frequency of LI'. Distribution of LI (intratumoral and extratumoral) was also assessed. The two pathologists (SM and RAAM) examined all specimens blinded from clinical data and from each other's results. Variability in reading between the two pathologists was assessed by a third pathologist (ARG) revealing excellent level of agreement, kappa value 0.81 , indicating almost perfect agreement. This study examined LI regardless the presence of blood vascular invasion, which was found to be a minor event in BC. ${ }^{8,15}$ It should also be noted that myoepithelial cells around ductal carcinoma in situ lesions show positive staining for podoplanin antibody; however, no difficulty was found in distinction between LI and ductal carcinoma in situ while conducting this study, this observation was discussed in detail previously. ${ }^{8,15,16}$

\section{Statistical Analysis}

Statistical analysis was performed using the software package SPSS for windows version 15; (1) a $2 \times 2$ table and $\chi^{2}$-test was conducted to examine for associations between LI and clinicopathological data, (2) Kaplan-Meier analysis and the log-rank 
test were used for survival analysis, and (3) multivariate analysis, using a Cox proportional hazards model, was conducted using the patient age, tumor size, tumor grade, HER-2 status, and LI. All statistical analyses were two sided and significance defined as $P<0.05$.

\section{Results}

\section{Clinicopathological Characters of the Patient Cohort}

In the following cohort of patients, $335(60 \%)$ were over 50 years of age, and $431(77 \%)$ tumors were larger than $1.5 \mathrm{~cm}$. Most of the tumors were of grade II and grade III; 207 (37\%) and 303 (54\%), respectively. Seventy-one percent of specimens were negative for estrogen receptor, $58 \%$ were negative for progesterone receptors, and $75 \%$ were negative for HER-2. Two hundred and fifty patients (45\%) developed recurrence, $228(40 \%)$ developed DM, and $226(40 \%)$ died from the disease.

\section{Frequency and Distribution of LI within Tumors}

LI was detected in 262/557 (47\%) of specimens. In the LI-positive specimens, 199 (76\%) specimens had peritumoral LI and $122(47 \%)$ had LIs involving intratumoral vessels. One hundred and forty-one specimens had LI of the peritumoral vessels only, 63 specimens had LI in the intratumoral vessels only and 58 specimens had the LI in both intra- and peritumoral vessels.

\section{Association between LI and Clinicopathological Criteria}

LI was significantly higher in patients younger than 50 years where $56 \%$ of LI-positive specimens were $<50$ years old, $P=0.001$. Poorly differentiated tumors had higher rates of LI than well-differentiated tumors, $P<0.0001$. Specimens $(15,41$, and $56 \%$ ) in grade I, II, and III, respectively, were LI positive. Larger tumors $(>1.5 \mathrm{~cm}$ ) had more frequent LI where $49 \%$ of tumors $>1.5 \mathrm{~cm}$ size were LIpositive tumors compared with $40 \%$ of tumors $<1.5 \mathrm{~cm}$, however, this was not significant, $P=0.057$.

Breast cancers with basal phenotype (specimens with positive expression of CK5/6 and/or CK14) were identified. There was no difference between basal and non-basal phenotypes in association with the presence of LI. Fifty percent of BCs with basal phenotype and $47 \%$ of non-basal group had positive LI $(P=0.588)$. More information about vascular characteristics and LI in basal and triple-negative BC was reported in a previous study. ${ }^{17} \mathrm{LI}$ occurred at significantly higher rate with higher expression of HER-2. LI positivity was $71 \%$ in HER-2-positive immunohistochemistry score 3 group compared with $45 \%$ in HER-2 score 0 group $(P=0.006)$. The associations between LI and other clinicopathological features are shown in Table 1.

In conclusion, presence of LI in LN-positive BC is significantly associated with higher grade tumors, higher HER-2 expression, and negativity for hormonal receptors but not with tumor size, with basal or triple-negative phenotypes.

\section{Frequency of LI and Relationship to Survival}

The frequency of LI in the LI-positive specimens ranged from 1 per section to 350 per section. Fiftytwo $(20 \%)$ of the specimens had only a single LI in the tumor section, 129 (49\%) had $\leq 3$ LIs, and 204 $(78 \%)$ had $\leq 10$ LIs. To examine whether specimens that had a higher frequency of LIs in their primary tumor had a more frequent recurrence or death rate from the disease, survival analysis was conducted

Table 1 Association between LI and clinicopathological features

\begin{tabular}{|c|c|c|c|c|}
\hline \multicolumn{5}{|c|}{ Presence of LI no. (\%) } \\
\hline & Absent & Present & Total & $\mathrm{P}$-value \\
\hline \multicolumn{5}{|l|}{ Age } \\
\hline$\leq 50$ years & $97(44)$ & $125(56)$ & $222(40)$ & \\
\hline$>50$ years & $198(59)$ & $137(41)$ & $335(60)$ & 0.001 \\
\hline \multicolumn{5}{|c|}{ Menopausal status } \\
\hline Pre & $196(61)$ & 125 (39) & $321(58)$ & \\
\hline Post & $99(41)$ & $137(58)$ & $236(42)$ & $<\mathbf{0 . 0 0 0 1}$ \\
\hline \multicolumn{5}{|l|}{ Size } \\
\hline$<1.5 \mathrm{~cm}$ & $75(60)$ & $51(40)$ & $126(23)$ & \\
\hline$>1.5 \mathrm{~cm}$ & $220(51)$ & $211(49)$ & $431(77)$ & 0.057 \\
\hline \multicolumn{5}{|l|}{ Grade } \\
\hline I & $40(85)$ & $7(15)$ & 47 (8) & \\
\hline II & $123(59)$ & $84(41)$ & $207(37)$ & \\
\hline III & $132(44)$ & $171(56)$ & $303(54)$ & $<\mathbf{0 . 0 0 0 1}$ \\
\hline \multicolumn{5}{|c|}{ No. of positive lymph nodes } \\
\hline 1 & $154(58)$ & $114(42)$ & 268 & \\
\hline 2 & $63(58)$ & $46(42)$ & 109 & \\
\hline 3 & $31(43)$ & $41(57)$ & 72 & \\
\hline$>3$ & $47(43)$ & $61(57)$ & 108 & 0.019 \\
\hline \multicolumn{5}{|c|}{ Basal phenotype } \\
\hline Non-basal & $224(53)$ & $198(47)$ & $422(80)$ & \\
\hline Basal & $53(50)$ & $53(50)$ & $106(20)$ & $P=0.588$ \\
\hline \multicolumn{5}{|c|}{ Estrogen receptor } \\
\hline Negative & $55(37)$ & $96(64)$ & $151(29)$ & \\
\hline Positive & $221(59)$ & $154(41)$ & $375(71)$ & $<\mathbf{0 . 0 0 0 1}$ \\
\hline \multicolumn{5}{|c|}{ Progesterone receptor } \\
\hline Negative & $92(41)$ & $131(59)$ & $223(42)$ & \\
\hline Positive & $185(60)$ & 119 (39) & $304(58)$ & $<\mathbf{0 . 0 0 0 1}$ \\
\hline \multicolumn{5}{|l|}{ HER-2 status } \\
\hline 0 & $223(55)$ & $184(45)$ & $407(75)$ & \\
\hline 1 & 34 (59) & $24(41)$ & $58(11)$ & \\
\hline 2 & $15(51)$ & $14(48)$ & $29(5)$ & \\
\hline 3 & $13(28)$ & $33(71)$ & $46(9)$ & 0.006 \\
\hline
\end{tabular}

Abbreviation: LI, lymphatic invasion.

Bold values indicate statistically significant associations. 
after categorization of the specimens into different subgroups according to the frequency of LI: (a) specimens with $1,2,3$, or $>3$ LIs; (b) specimens with $\leq 3,4-10$, and $>10$ LIs; (c) specimens with $\leq 5,6-10$, and $>10$ LIs; and (d) specimens with $\leq 10,11-20$, and $>20$ LIs. No significant difference in OS was found between any of the groups; $P=0.877, \quad P=0.632, \quad P=0.711, \quad$ and $P=0.125$, respectively (Supplementary Figure 1). The same analysis was conducted in terms of DFI and DM and, similarly, no significant association was found. The only significant difference was regarding presence of LI (either single or numerous LIs) or absence of LI.

The negative impact of LI on patient outcome was found to be due to the presence of peritumoral LI but not intratumoral LI. Peritumoral LI was significantly associated with occurrence of recurrence, DM, and death from the disease, $P<0.0001, P<0.0001$, and $P<0.0001$, respectively, whereas intratumoral LI was not significantly associated with any of these events, $P=0.154, P=0.472$, and $P=0.262$, respectively.

Increasing number of vessels involved with LI is not associated with increasing risk for recurrence, metastasis, or death from LN-positive BC.

\section{Prognostic Impact of LI in Whole LN-Positive BC Specimens}

Patients who developed disease recurrence or DM had a significantly higher LI-positive status. LI positivity was detected in 142/250 (57\%) of patients with recurrent tumors in comparison to $38 \%$ with non-recurrent tumors, $P<0.0001$. Similarly, $127 / 250$ $(51 \%)$ of tumors that developed DM had positive LI compared with $36 \%$ of tumors that did not metastasize, $P<0.0001$. The most common sites for the $\mathrm{DM}$ in LN-positive breast cancers were the bone, liver, brain, and lung. It was interesting to find that LI was highest in specimens that had DM to the liver, whereas there was no difference in the frequency of LI in specimens with DM to bone, brain, or lung (detailed figures are summarized in Table 2).

The 20-year OS rate and DFI rate were $72 \%$ in patients without LI compared with $54 \%$ in patients with LI $(P<0.0001)$ for OS and was $61 \%$ in LInegative tumors compared with $43 \%$ in LI-positive tumors for DFI $(P<0.0001)$, Table 3 and Figure 1. When tumor size, tumor grade, HER-2 status, estrogen receptor status, progesterone receptor status, and LI were used in multivariate analysis, tumor size $(P=0.003)$, tumor grade $(P<0.0001)$, HER-2 status $(P=0.015)$, and LI $(P=0.024)$ retained significance in relation to OS. In multivariate analysis for DFI, tumor grade $(P=0.048)$, HER-2 status $(P=0.017)$, and LI $(P=0.003)$ remained significant after adjusted to other variables (Table 4).

In whole LN-positive BC, presence of LI along with higher tumor grade and higher HER-2 expression is
Table 2 Sites and frequencies of distant metastases in LI-positive specimens

\begin{tabular}{lrrr} 
Sites for distant metastasis & LI absent & LI present & Total \\
\hline Metastasis negative & & & \\
$\quad$ None & 188 & 132 & 320 \\
& & & \\
Metastasis positive & 42 & 42 & 84 \\
$\quad$ Bone & 2 & 4 & 6 \\
Brain (alone) & 12 & 7 & 19 \\
Brain (plus liver/lung/bone or pleura) & 8 & 13 & 21 \\
Liver (alone) & 10 & 26 & 36 \\
Liver (plus brain/lung/bone or pleura) & 6 & 6 & 12 \\
Lung & 27 & 32 & 59 \\
Others & 295 & 262 & 557 \\
Total & & & \\
\hline
\end{tabular}

Abbreviation: LI, lymphatic invasion.

an independent poor prognostic factor for occurrence of recurrence, DM, and death from the disease.

\section{Relationship between Presence of LI and Patient Outcome According to the Number of Positive LNs}

For further patient stratification, specimens were divided into four groups according to the number of positive LNs: (a) group 1 with a single positive LN, (b) group 2 with two positive LNs, (c) group 3 with three positive LNs, and (d) group 4 with more than three positive LNs. Presence of LI was significantly associated with poor prognosis in tumors with single positive LN but was not significant in tumors with more than one positive LN as shown in Table 5 and Figure 2. In specimens with a single positive LN, the 20 -year OS was $80 \%$ in LI-negative tumors compared with $64 \%$ in LI positives $(P=0.021)$. Similarly, the 20 -year DFI rate was $74 \%$ in LInegative tumors compared with $48 \%$ in LI positive ones $(P<0.0001)$, and for DM it was $76 \%$ in LI negative compared with $58 \%$ in LI-positive cases $(P=0.002)$. However, in multivariate analysis, LI lost its significant association with poor prognosis after inclusion of tumor size $(P=0.026)$, tumor grade $(P=0.049)$, estrogen receptor $(P=0.897)$, progesterone receptor $(P=0.456)$, and HER-2 status $(P=0.060)$. Survival figures in the four groups are shown in Table 5.

It was of interest to find the difference in prognosis between two groups of BC; (single LN-positive/LI-positive) carcinoma against (LN-negative/LI-positive) carcinoma. To do this, we retrieved LI data recorded in 1000 LN-negative BC specimens that was published in a previous article assessing LI using podoplanin antibody. ${ }^{8}$ Survival analysis revealed that there is an overlap between the survival curves of the two groups with no significant difference between both $(P=0.324)$ (Figure 2f).

In conclusion, $\mathrm{LI}$ is a poor prognostic factor in LNpositive BC that has a single positive LN but not in 
Table 3 Association between LI and patient outcome using univariate survival analysis in the whole lymph node-positive breast carcinoma specimens

\begin{tabular}{|c|c|c|c|c|c|c|c|c|c|c|}
\hline & \multicolumn{2}{|c|}{ Overall survival } & \multicolumn{2}{|c|}{ Disease-free interval } & \multicolumn{2}{|c|}{ Recurrence } & \multicolumn{2}{|c|}{ Local recurrence } & \multicolumn{2}{|c|}{ Distant metastasis } \\
\hline & $\begin{array}{l}\text { No. of deaths/ } \\
\text { no. of patients }\end{array}$ & $\begin{array}{l}\text { 20-year } \\
\text { survival } \\
\text { rate }\end{array}$ & $\begin{array}{l}\text { No. of events/ } \\
\text { no. of } \\
\text { patients }\end{array}$ & $\begin{array}{l}\text { 20-year } \\
\text { survival } \\
\text { rate }\end{array}$ & $\begin{array}{l}\text { No. of events/ } \\
\text { no. of } \\
\text { patients }\end{array}$ & $\begin{array}{l}\text { 20-year } \\
\text { survival } \\
\text { rate }\end{array}$ & $\begin{array}{l}\text { No. of events/ } \\
\text { no. of } \\
\text { patients }\end{array}$ & $\begin{array}{l}\text { 20-year } \\
\text { survival } \\
\text { rate }\end{array}$ & $\begin{array}{l}\text { No. of events/ } \\
\text { no. of } \\
\text { patients }\end{array}$ & $\begin{array}{l}\text { 20-year } \\
\text { survival } \\
\text { rate }\end{array}$ \\
\hline \multirow{3}{*}{$\begin{array}{l}\text { LI } \\
\text { absent } \\
\text { LI } \\
\text { present }\end{array}$} & $79 / 279$ & 72 & $108 / 279$ & 61 & $50 / 279$ & 94 & $22 / 279$ & 92 & $101 / 279$ & 65 \\
\hline & $114 / 250$ & 54 & $142 / 250$ & 43 & $36 / 212$ & 83 & $31 / 250$ & 87 & $127 / 250$ & 51 \\
\hline & & $<0.0001$ & & $<0.0001$ & & $<0.0001$ & & 0.055 & & $<0.0001$ \\
\hline
\end{tabular}

Abbreviation: LI, lymphatic invasion.

Bold italic values indicate statistical significant $P$-values.
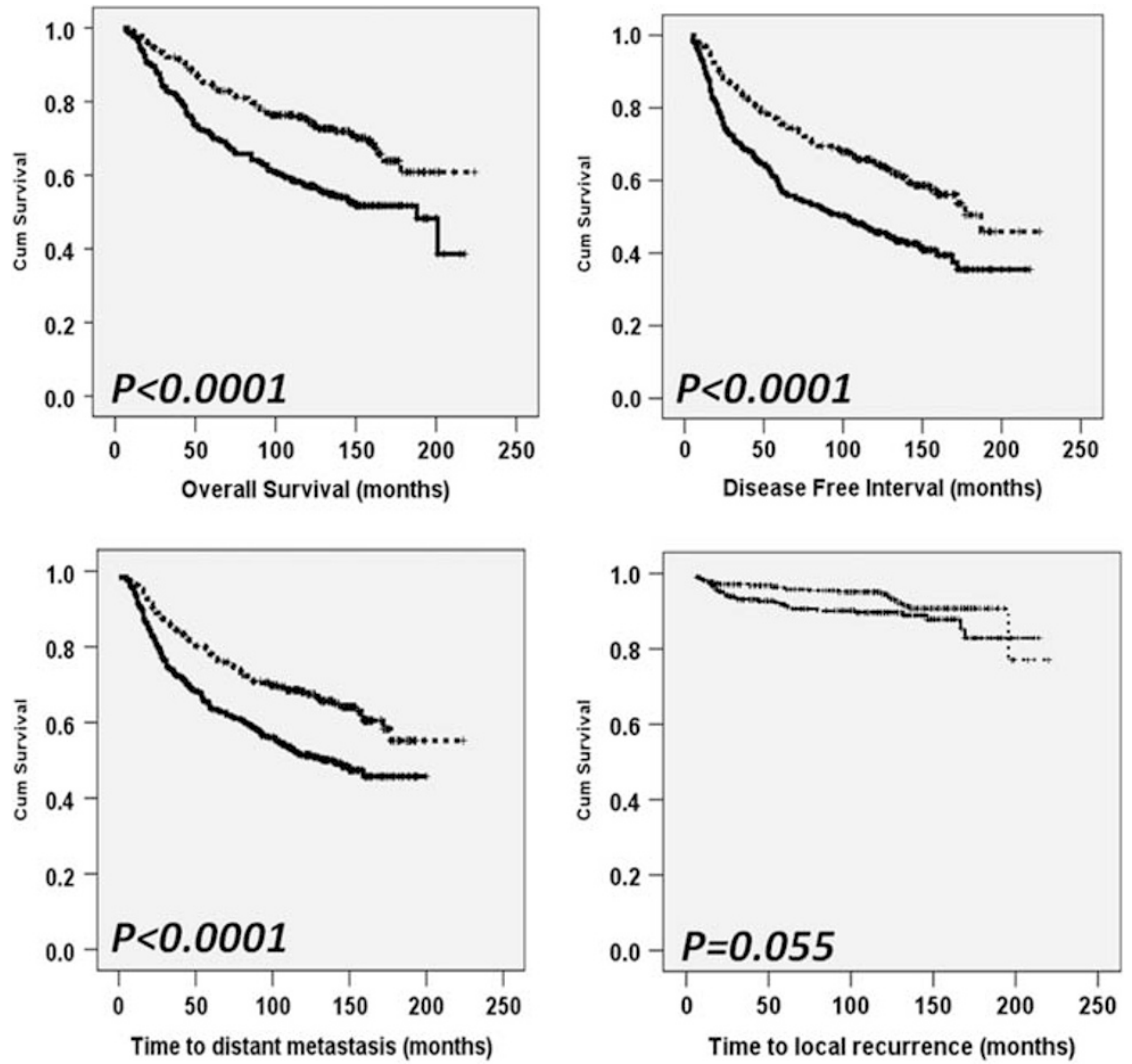

Figure 1 Survival analysis and Kaplan-Meier curves for the presence of lymphatic invasion (LI) in whole lymph node-positive breast cancer patients. Dashed line represents LI-negative breast cancer, continuous black line represents LI-positive breast cancer patients. First upper left panel for overall survival, upper right for disease-free interval, lower left for distant metastasis and lower right for local recurrence. Survival time is in months.

BC with more than one positive LN. The outcome of single LN-positive BC/LI-positive tumors is more toward the prognosis of LN-negative/LI-positive tumors and not toward the LN-positive group.

\section{Relationship between Presence of LI and Patient Outcome in T1N1 and T2N1 Breast Cancers}

In T1N1 stage (226 specimens), LI was highly associated with poor OS $(P=0.002)$, DFI $(P<0.0001)$, and DM $(P<0.0001)$ in univariate analysis (Supplementary Figure 2). However, LI lost its significance for OS and for DM after adjustment to tumor size, grade, estrogen receptors, progesterone receptor, and HER-2 status. LI retained significance for DFI ( $P=0.041$; HR: 1.705; 95\% CI: 0.983-2.958).

Tumors of T2N1 stage were separated and were analyzed for survival. LI was not associated with OS or risk for DM but was associated with shorter DFI ( $P$-values were $0.119,0.092$, and 0.037 , respectively) (Supplementary Figure 3). However, after 
Table 4 Multivariate analysis for whole lymph node-positive breast carcinoma specimens

\begin{tabular}{|c|c|c|c|c|c|c|c|c|}
\hline & \multicolumn{4}{|c|}{ Overall survival } & \multicolumn{4}{|c|}{ Disease-free interval } \\
\hline & \multirow[b]{2}{*}{ Hazard ratio } & \multirow[b]{2}{*}{ P-value } & \multicolumn{2}{|c|}{$C I$} & \multirow[b]{2}{*}{ Hazard ratio } & \multirow[b]{2}{*}{ P-value } & \multicolumn{2}{|c|}{$C I$} \\
\hline & & & Upper & Lower & & & Upper & Lower \\
\hline Age & 1.172 & 0.310 & 0.862 & 1.593 & 0.886 & 0.378 & 0.862 & 1.159 \\
\hline Tumor size $(\leq 1.5 \mathrm{~cm}$ vs $>1.5 \mathrm{~cm})$ & 1.925 & 0.003 & 1.253 & 2.959 & 1.782 & 0.002 & 1.240 & 2.561 \\
\hline Tumor grade (overall) & & 0.000 & & & & 0.013 & 0.672 & 2.335 \\
\hline Tumor grade (II vs I) & 3.055 & 0.063 & 0.939 & 9.934 & 1.253 & 0.479 & 1.006 & 3.505 \\
\hline Tumor grade (III vs I) & 7.107 & 0.001 & 2.207 & 22.888 & 1.877 & 0.048 & 0.944 & 2.099 \\
\hline ER (negative vs positive) & 1.265 & 0.286 & 0.821 & 1.950 & 1.407 & 0.094 & 0.586 & 1.168 \\
\hline PR (negative vs positive) & 0.744 & 0.132 & 0.506 & 1.093 & 0.827 & 0.281 & 0.772 & 1.796 \\
\hline HER-2 (overall) & & 0.015 & & & & 0.017 & 0.860 & 2.607 \\
\hline HER-2 (I vs 0) & 1.473 & 0.102 & 0.926 & 2.341 & 1.177 & 0.449 & 1.245 & 2.860 \\
\hline HER-2 (II vs I) & 1.388 & 0.285 & 0.761 & 2.532 & 1.497 & 0.154 & 1.121 & 1.927 \\
\hline HER-2 (III vs I) & 1.947 & 0.004 & 1.244 & 3.047 & 1.887 & 0.003 & 1.240 & 2.561 \\
\hline LI (absent vs present) & 1.427 & 0.024 & 1.049 & 1.941 & 1.470 & 0.005 & 0.672 & 2.335 \\
\hline
\end{tabular}

Abbreviations: CI, confidence interval; LI, lymphatic invasion.

Bold italic values indicate statistical significant $P$-values.

Table 5 Survival analysis for overall survival, recurrence, local recurrence, and distant metastasis according to the status of LI and according to the number of positive lymph nodes

\begin{tabular}{|c|c|c|c|c|c|c|c|c|}
\hline & \multicolumn{2}{|c|}{ One positive lymph node } & \multicolumn{2}{|c|}{ Two positive lymph nodes } & \multicolumn{2}{|c|}{ Three positive lymph nodes } & \multicolumn{2}{|c|}{$\begin{array}{c}\text { More than three positive } \\
\text { lymph nodes }\end{array}$} \\
\hline & $\begin{array}{l}\text { No. of events/no. } \\
\text { of patients }\end{array}$ & $\begin{array}{c}20 \% \\
\text { survival } \\
\text { rate }\end{array}$ & $\begin{array}{l}\text { No. of events/no. } \\
\text { of patients }\end{array}$ & $\begin{array}{c}20 \% \\
\text { survival } \\
\text { rate }\end{array}$ & $\begin{array}{l}\text { No. of events/no. } \\
\text { of patients }\end{array}$ & $\begin{array}{c}20 \% \\
\text { survival } \\
\text { rate }\end{array}$ & $\begin{array}{l}\text { No. of events/no. } \\
\text { of patients }\end{array}$ & $\begin{array}{c}20 \% \\
\text { survival } \\
\text { rate }\end{array}$ \\
\hline \multicolumn{9}{|c|}{ Overall survival } \\
\hline LI absent & $30 / 150$ & 80 & $13 / 59$ & 78 & $14 / 30$ & 53 & $22 / 40$ & 45 \\
\hline LI present & $39 / 110$ & 64 & $13 / 144$ & 70 & $22 / 41$ & 46 & $40 / 55$ & 27 \\
\hline & & 0.021 & & 0.260 & & 0.246 & & 0.088 \\
\hline \multicolumn{9}{|c|}{ Disease-free interval } \\
\hline LI absent & $39 / 150$ & 74 & $23 / 59$ & 61 & $19 / 30$ & 37 & $27 / 40$ & 33 \\
\hline LI present & $457 / 110$ & 48 & $20 / 44$ & 54 & $24 / 41$ & 41 & $41 / 55$ & 26 \\
\hline & & $<0.0001$ & & 0.371 & & 0.703 & & 0.239 \\
\hline \multicolumn{9}{|l|}{ Recurrence } \\
\hline LI absent & $4 / 150$ & 97 & $6 / 59$ & 90 & $4 / 30$ & 87 & $7 / 40$ & 83 \\
\hline LI present & $8 / 110$ & 92 & $3 / 44$ & 93 & $2 / 41$ & 95 & $9 / 55$ & 84 \\
\hline & & 0.077 & & 0.695 & & 0.287 & & 0.872 \\
\hline \multicolumn{9}{|c|}{ Local recurrence } \\
\hline LI absent & $10 / 150$ & 93 & $6 / 59$ & 90 & $3 / 30$ & 96 & $3 / 40$ & 92 \\
\hline LI present & $13 / 110$ & 88 & $6 / 44$ & 86 & $3 / 41$ & 93 & $9 / 55$ & 84 \\
\hline & & 0.211 & & 0.527 & & 0.824 & & 0.205 \\
\hline \multicolumn{9}{|c|}{ Distant metastasis } \\
\hline LI absent & $36 / 152$ & 76 & $15 / 62$ & 76 & $17 / 30$ & 43 & $33 / 47$ & 30 \\
\hline \multirow[t]{2}{*}{ LI present } & $48 / 114$ & 58 & $14 / 44$ & 68 & $23 / 41$ & 44 & $42 / 66$ & 30 \\
\hline & & 0.002 & & 0.361 & & 0.428 & & 0.555 \\
\hline
\end{tabular}

Abbreviation: LI, lymphatic invasion.

Bold italic values indicate statistical significant $P$-values.

adjustment to other prognostic factors, LI lost significance.

Presence of LI is a poor prognostic factor in tumors smaller than $2 \mathrm{~cm}$ in size with $\mathrm{N} 1$ nodal stage but not in tumors larger than $2 \mathrm{~cm}$ in the same nodal group.

\section{Discussion}

The poor prognostic significance of vascular invasion in $\mathrm{BC}$ as a whole and in $\mathrm{LN}$-negative patients in particular has been recognized in previous several studies. ${ }^{7,8,12,15}$ However, its prognostic role in LN- 
a

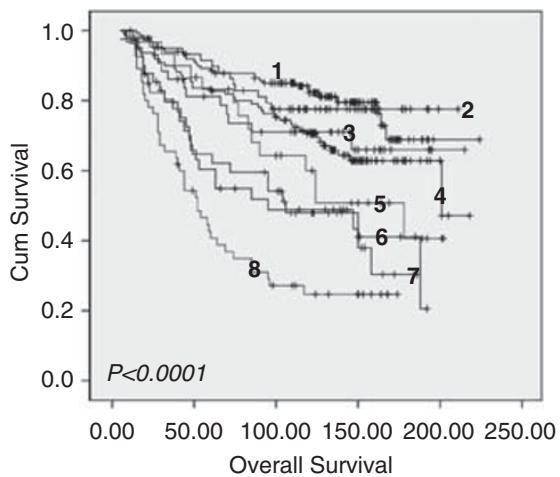

d

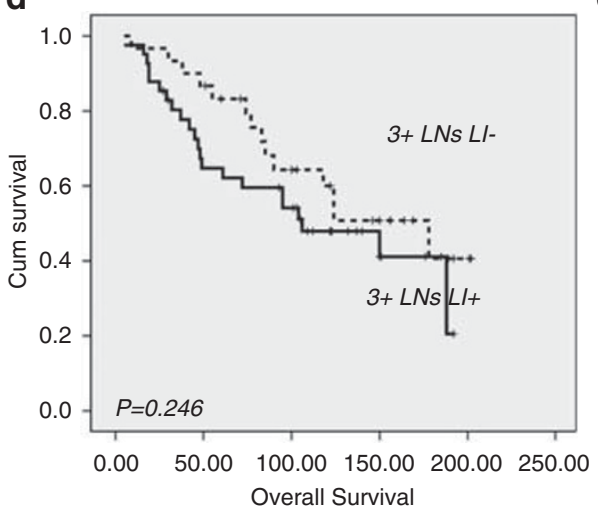

b

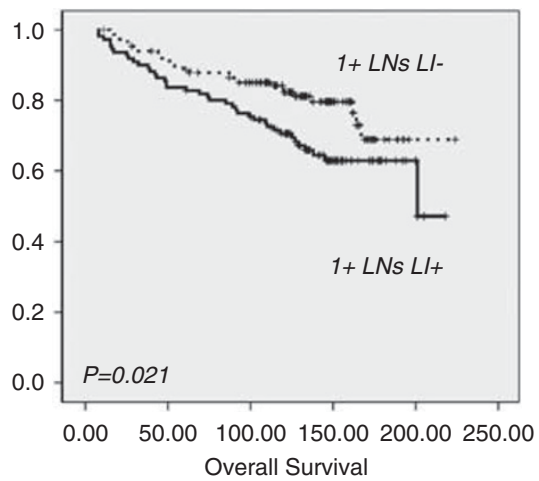

e

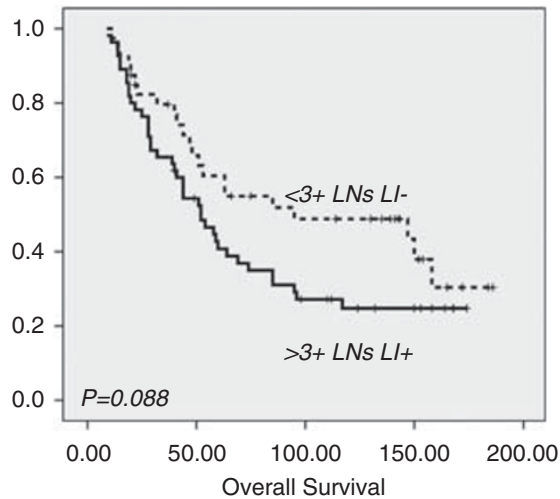

C

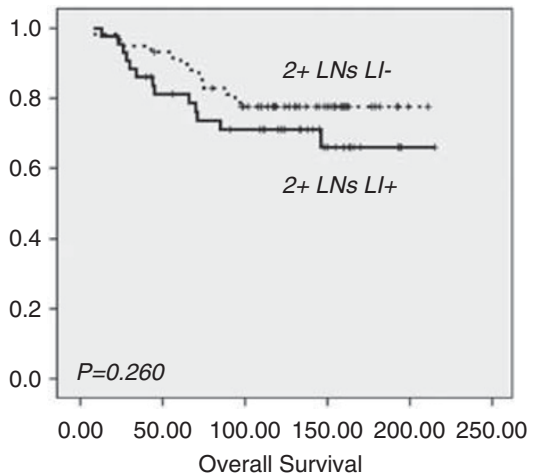

f

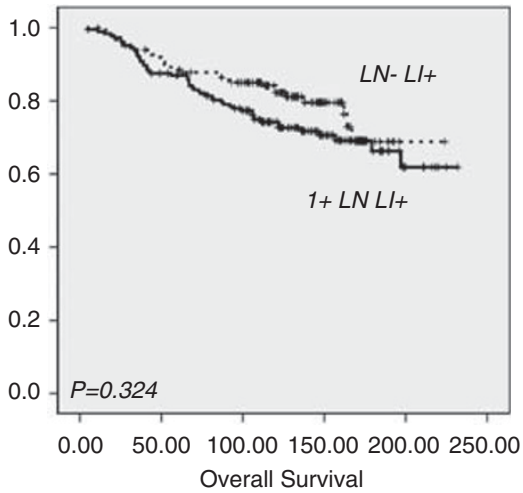

Figure 2 Survival analysis and Kaplan-Meier curves showing influence of the presence of lymphatic invasion (LI) on patient overall survival in different patient groups. (a) shows survival curves for lymph node-positive breast cancer patients according to the number of affected lymph nodes with and without LI labeled as follows: line 1, one positive lymph node/LI negative; line 2, one positive lymph node/LI positive; line 3, two positive lymph nodes/LI negative; line 4, two positive lymph nodes/LI positive; line 5, three positive lymph nodes/LI negative; line 6, three positive lymph nodes/LI positive; line 7, > 3 positive lymph nodes/LI negative; line 8, > 3 positive lymph nodes/LI positive. (b) Patients with a single positive lymph node, (c) patients with two positive lymph nodes, (d) patients with three positive lymph nodes, (e) survival curves of two groups; patients with three or less positive lymph nodes and patients with more than three positive lymph nodes. (f) Shows survival curves of two groups; group (1), lymph node-negative/LI-positive patients and group (2), patients with a single positive lymph node/LI positive.

positive patients is still questionable. ${ }^{18,19}$ Because invasion of lymph vessels was found to be the predominant type of lymphovascular invasion in breast cancer with minor role for blood vascular invasion, ${ }^{8,15}$ the current study assessed only LI in LN-positive BC.

In the study specimens, presence of LI in LNpositive BC as a whole was significantly associated with poorer survival (shorter DFI and shorter OS) using univariate analysis and also multivariate analysis. In a similar study that examined vascular invasion using $\mathrm{H} \& \mathrm{E}$-stained sections in $374 \mathrm{LN}$ positive $\mathrm{BC}$ specimens, it was found to be an independent poor prognostic factor for development of DM. ${ }^{13}$

To determine in more detail the prognostic significance of LI in subgroups of BC according to number of positive axillary LNs, patients were divided into four groups (patients with one, two, three and more than three positive LNs). LI was significantly associated with shorter OS, shorter DFI, and higher risk for DM in patients with single positive LN, but not with patients having two, three or more than three positive LNs. A previous study by Woo et $a l^{20}$ examined 1258 patients with invasive BC with 12-year follow-up reported that presence of vascular invasion is a poor prognostic factor both in LN-negative and in LN-positive disease. They also found that this prognostic significance is most meaningful in N1 stage of BC.

It was of interest to find no significant difference in survival between LN-negative/LI-positive BC and patients having single LN-positive/LI-positive BC. The survival analysis showed overlapping survival curves between the two groups. It has long been accepted that presence of LI is a surrogate for positive LN. This finding, however, challenges this fact at least in BC with a single positive LN where the presence of LI has negative impact on patient outcome. Three indications can be inferred from this observation: (a) patients with a single positive LN/LI positive can be considered a subcategory within the N1 stage of BC. The outcome of those patients seems to be closer toward the outcome of LN-negative/LI-positive 
group rather than to the LN-positive group as a whole. (b) LI is another poor prognostic factor that can be used in management decision in patients with single positive LN, and (c) BC with single positive LN may be a transition phase between LNnegative and LN-positive BC. It is worth noting that no attempts were made in this study to separate the group of LN micrometastasis or to find the difference of LI impact on this subgroup vs tumors that have LN deposits $>0.2 \mathrm{~cm}$ or other groups. It would be interesting to study the association between LI and micrometastasis and its biological significance.

Searching the literature for other studies that assessed LI in LN-positive BC revealed five studies; the findings of which are summarized in Table 6. Findings from these studies and from the current study indicate that LI-positive BCs with a single positive LN are at higher risk of adverse events and reduced survival and potentially could warrant additional therapy.

The presence of LI in LN-positive BC was found to be more frequent in tumors of larger size, higher grade, with higher HER-2 expression (HER-2 score3 ), and with negativity for estrogen receptor and for progesterone receptor. The same findings were reported in many previous studies ${ }^{21-24}$ and from previous findings by our group. $2,7,8,15,25,26$

The rate of LI in the current study was $47 \%$, which lies in the same range as that reported in other studies: $28 \%,{ }^{20} 46 \%,{ }^{13}$ and $55 \%{ }^{27}$ of patients with LN-positive BC in different patient cohorts. In our specimens, most of the LI lesions were detected in the peritumoral vessels $(76 \%$ of LI-positive specimens). Studies that examined the physical dynamics of malignant proliferating tumors have shown that the intratumoral pressure is higher than that in the peritumoral area, which could cause collapse of the intratumoral lymph vessels. ${ }^{28}$ This could then hamper invasion of lymph vessels by the invasive tumor cells. We and others had shown that intratumoral lymphatics with tumor emboli do exist; however, most of the LI lesions are located in peritumoral vessels. ${ }^{8,29-31}$

We have also examined whether the frequency of LI per tumor tissue affects outcome in LN-positive tumors. In our previous study assessing LI in 1000 LN-negative BC, number of LI foci ranged from 1 to 79 per tumor section. The frequency of LI per tumor tissue was found to have no effect on patient outcome in terms of risk for death, recurrence or development of DM. ${ }^{8}$ In the current study, LI lesions ranged from 1 to 350 invasions per tumor section. Similar to LNnegative BC, the frequency of LI had no effect on outcome in LN-positive BC patients. It has been suggested that extensive LI lesions in the peritumoral area is associated with a worse prognosis than tumors with low LI frequency, ${ }^{11}$ however, our current data and previous data ${ }^{8}$ do not support this view.

Table 6 Studies examined prognostic role of LI in lymph node-positive breast cancer

Survival analysis

\begin{tabular}{|c|c|c|c|c|c|c|c|c|c|}
\hline Place of study & $\begin{array}{l}\text { Number } \\
\text { of } \\
\text { patients }\end{array}$ & $\begin{array}{l}\text { Method } \\
\text { of detection } \\
\text { of LI }\end{array}$ & $\begin{array}{l}\% \text { of } L I \\
\text { positivity }\end{array}$ & $\begin{array}{l}\text { Follow-up } \\
\text { period } \\
\text { (min-max) }\end{array}$ & $\begin{array}{l}\text { Significant association } \\
\text { between presence of } \\
\text { LI and clinicopathological } \\
\text { characteristics }\end{array}$ & $\begin{array}{l}\text { Distant } \\
\text { metastasis }\end{array}$ & $\begin{array}{l}\text { Overall } \\
\text { survival }\end{array}$ & $\begin{array}{l}\text { Disease-free } \\
\text { interval }\end{array}$ & Reference \\
\hline $\begin{array}{l}\text { Current study } \\
\text { Department of } \\
\text { Histopathology, Breast } \\
\text { cancer institute, City } \\
\text { Hospital, University } \\
\text { of Nottingham, UK }\end{array}$ & 557 & $\begin{array}{l}\text { IHC with } \\
\text { anti- } \\
\text { podoplanin }\end{array}$ & $47 \%$ & $(4-246)$ & $\begin{array}{l}\text { Significantly associated } \\
\text { with higher tumor grade, } \\
\text { high HER-2 score, negative } \\
\text { ER and PR status, and } \\
\text { number of affected LNs } \\
\text { Not significantly associated } \\
\text { with tumor size or basal } \\
\text { phenotype }\end{array}$ & $\begin{array}{l}\text { + ve in UV and } \\
\text { MV in whole } \\
\text { group } \\
+ \text { ve in UN in } \\
\text { T1N1 } \\
\text { - ve in T1N2 }\end{array}$ & $\begin{array}{l}\text { + ve in UV and } \\
\text { MV in whole } \\
\text { group } \\
\text { + ve in UN in } \\
\text { T1N1 } \\
\text { - ve in T1N2 }\end{array}$ & $\begin{array}{l}\text { + ve in UV and } \\
\text { MV in whole } \\
\text { group } \\
\text { + ve in UN in } \\
\text { T1N1 } \\
\text { - ve in T1N2 }\end{array}$ & - \\
\hline $\begin{array}{l}\text { Bergonie institute, } \\
\text { France }\end{array}$ & 374 & $\mathrm{H} \& \mathrm{E}$ & $46 \%$ & $\begin{array}{l}136-155 \\
\text { months }\end{array}$ & $\begin{array}{l}\text { Significantly associated } \\
\text { with grade III Trs, age } \\
<40 \text { years and ER negativity } \\
\text { Not significantly associated } \\
\text { with Tr size or number of } \\
\text { positive lymph nodes }\end{array}$ & $\begin{array}{l}+ \text { ve in UV and } \\
\text { MV analysis in } \\
\text { whole group }\end{array}$ & $\begin{array}{l}+ \text { ve in UV and } \\
\text { MV analysis in } \\
\text { whole group }\end{array}$ & $\begin{array}{l}+ \text { ve in UV and } \\
\text { MV analysis in } \\
\text { whole group }\end{array}$ & 13 \\
\hline $\begin{array}{l}\text { Chonnam National } \\
\text { University Medical } \\
\text { School, Gwangju, } \\
\text { Korea }\end{array}$ & 349 & H\&E & $55 \%$ & $\begin{array}{l}12-78 \\
\text { months }\end{array}$ & $\begin{array}{l}\text { Significantly associated } \\
\text { with grade III Trs, age } \\
<40 \text { years and ER negativity } \\
\text { and not with progesterone } \\
\text { receptor status, HER-2 } \\
\text { status, or p53 status. }\end{array}$ & NA & $\begin{array}{l}\text { + ve in UV and } \\
\text { MV analysis in } \\
\text { whole group } \\
\text { Analysis in } \\
\text { subgroups was } \\
\text { not done }\end{array}$ & $\begin{array}{l}\text { + ve in UV and } \\
\text { MV analysis in } \\
\text { whole group } \\
\text { Analysis in } \\
\text { subgroups was } \\
\text { not done }\end{array}$ & 27 \\
\hline $\begin{array}{l}\text { Tarzana Hospital, } \\
\text { University of south } \\
\text { California, and USC/ } \\
\text { Norris comprehensive } \\
\text { cancer center, } \\
\text { Los Angeles, USA }\end{array}$ & 504 & $\mathrm{H} \& \mathrm{E}$ & $28 \%$ & 48 months & Not reported & NA & $\begin{array}{l}\text { + ve in UV in pN1 } \\
\text { - ve in pN2 }\end{array}$ & $\begin{array}{l}\text { + ve in UV in pN1 } \\
\text { - ve in } \mathrm{pN} 2\end{array}$ & 20 \\
\hline
\end{tabular}

Abbreviations: IHC, immunohistochemistry; H\&E, haematoxylin and eosin; LI, lymphatic invasion; MV, multivariate; NA, not applicable; UV, univariate. 
In conclusion, $\mathrm{LI}$ is a poor prognostic factor in LNpositive BC, particularly for patients having single positive LN. LI therefore may be considered when assessing risk of adverse events in patients with breast cancer. We recommend incorporation of LI in BC-staging protocols and in prognostic indices.

\section{Acknowledgments}

We thank Egyptian government, Assiut University, Faculty of Medicine, QAU for funding this work (grant number 1016).

\section{Disclosure/conflict of interest}

The authors declare no conflict of interest.

\section{References}

1 Marinho VF, Metze K, Sanches FS, et al. Lymph vascular invasion in invasive mammary carcinomas identified by the endothelial lymphatic marker D2-40 is associated with other indicators of poor prognosis. BMC Cancer 2008;8:64.

2 Mohammed RA, Ellis IO, Elsheikh S, et al. Lymphatic and angiogenic characteristics in breast cancer: morphometric analysis and prognostic implications. Breast Cancer Res Treat 2009;113:261-273.

3 Mittendorf EA, Sahin AA, Tucker SL, et al. Lymphovascular invasion and lobular histology are associated with increased incidence of isolated tumor cells in sentinel lymph nodes from early-stage breast cancer patients. Ann Surg Oncol 2008;15:3369-3377.

4 Truong PT, Yong CM, Abnousi F, et al. Lymphovascular invasion is associated with reduced locoregional control and survival in women with node-negative breast cancer treated with mastectomy and systemic therapy. J Am Coll Surg 2005;200:912-921.

5 Gurleyik G, Gurleyik E, Aker F, et al. Lymphovascular invasion, as a prognostic marker in patients with invasive breast cancer. Acta Chir Belg 2007;107: 284-287.

6 Lauria R, Perrone F, Carlomagno C, et al. The prognostic value of lymphatic and blood vessel invasion in operable breast cancer. Cancer 1995;76:1772-1778.

7 Pinder SE, Ellis IO, Galea M, et al. Pathological prognostic factors in breast cancer. III. Vascular invasion: relationship with recurrence and survival in a large study with long-term follow-up. Histopatho logy 1994;24:41-47.

8 Mohammed RA, Martin SG, Mahmmod AM, et al. Objective assessment of lymphatic and blood vascular invasion in lymph node-negative breast carcinoma: findings from a large case series with long-term followup. J Pathol 2011;223:358-365.

9 Davis BW, Gelber R, Goldhirsch A, et al. Prognostic significance of peritumoral vessel invasion in clinical trials of adjuvant therapy for breast cancer with axillary lymph node metastasis. Hum Pathol 1985;16:1212-1218.

10 Yildirim E, Berberoglu U. Local recurrence in breast carcinoma patients with T(1-2) and 1-3 positive nodes: indications for radiotherapy. Eur J Surg Oncol 2007;33:28-32.

11 Colleoni M, Rotmensz N, Maisonneuve P, et al. Prognostic role of the extent of peritumoral vascular invasion in operable breast cancer. Ann Oncol 2007;18: 1632-1640.

12 Rakha EA, Martin S, Lee AH, et al. The prognostic significance of lymphovascular invasion in invasive breast carcinoma. Cancer 2011;118:3670-3680.

13 Ragage F, Debled M, MacGrogan G, et al. Is it useful to detect lymphovascular invasion in lymph node-positive patients with primary operable breast cancer? Cancer 2010;116:3093-3101.

14 Galea MH, Blamey RW, Elston CE, et al. The Nottingham Prognostic Index in primary breast cancer. Breast Cancer Res Treat 1992;22:207-219.

15 Mohammed RA, Martin SG, Gill MS, et al. Improved methods of detection of lymphovascular invasion demonstrate that it is the predominant method of vascular invasion in breast cancer and has important clinical consequences. Am J Surg Pathol 2007;31:1825-1833.

16 Mohammed RA, Ellis IO, Lee $\mathrm{AH}$, et al. Vascular invasion in breast cancer; an overview of recent prognostic developments and molecular pathophysiological mechanisms. Histopathology 2009;55:1-9.

17 Mohammed RA, Ellis IO, Mahmmod AM, et al. Lymphatic and blood vessels in basal and triplenegative breast cancers: characteristics and prognostic significance. Mod Pathol 2011;24:774-785.

18 Yildirim E, Berberoglu U. Lymph node ratio is more valuable than level III involvement for prediction of outcome in node-positive breast carcinoma patients. World J Surg 2007;31:276-289.

19 Filleron T, Md FD, Kramar A, et al. Prognostic factors of young women ( $\leq 35$ years) with node positive breast cancer: possible influence on post-therapeutic followup. Bull Cancer 2013;100:22-29.

20 Woo CS, Silberman H, Nakamura SK, et al. Lymph node status combined with lymphovascular invasion creates a more powerful tool for predicting outcome in patients with invasive breast cancer. Am J Surg 2002;184:337-340.

21 Badwe RA, Md FD, Kramar A, et al. Prognostic factors of young women ( $<35$ years) with node positive breast cancer: possible influence on post-therapeutic followup. Bull Cancer 2013;100:22-293.

22 Bettelheim R, Penman HG, Thornton-Jones H, et al. Prognostic significance of peritumoral vascular invasion in breast cancer. Br J Cancer 1984;50:771-777.

23 Ejlertsen B, Jensen MB, Rank F, et al. Population-based study of peritumoral lymphovascular invasion and outcome among patients with operable breast cancer. J Natl Cancer Inst 2009;101:729-735.

24 Hartveit F, Thoresen S, Thorsen T, et al. Histological grade and efferent vascular invasion in human breast carcinoma. Br J Cancer 1981;44:81-84.

25 Elston CW, Ellis IO, Pinder SE. Pathological prognostic factors in breast cancer. Crit Rev Oncol Hematol 1999;31:209-223.

26 Lee AH, Pinder SE, Macmillan RD, et al. Prognostic value of lymphovascular invasion in women with lymph node negative invasive breast carcinoma. Eur J Cancer 2006;42:357-362.

27 Song YJ, Shin SH, Cho JS, et al. The role of lymphovascular invasion as a prognostic factor in patients with lymph node-positive operable invasive breast cancer. J Breast Cancer 2011;14:198-203. 
28 Padera TP, Kadambi A, di Tomaso E, et al. Lymphatic metastasis in the absence of functional intratumor lymphatics. Science 2002;296:1883-1886.

29 Bono P, Wasenius VM, Heikkila P, et al. High LYVE-1positive lymphatic vessel numbers are associated with poor outcome in breast cancer. Clin Cancer Res 2004;10:7144-7149.

30 Choi WW, Lewis MM, Lawson D, et al. Angiogenic and lymphangiogenic microvessel density in breast carci- noma: correlation with clinicopathologic parameters and VEGF-family gene expression. Mod Pathol 2005;18:143-152.

31 Van der Auwera I, Van Laere SJ, Van den Eynden GG, et al. Increased angiogenesis and lymphangiogenesis in inflammatory versus noninflammatory breast cancer by real-time reverse transcriptase-PCR gene expression quantification. Clin Cancer Res 2004;10: 7965-7971.

Supplementary Information accompanies the paper on Modern Pathology website (http://www.nature.com/ modpathol) 